\title{
Poupança externa e performance macroeconômica: Uma Análise a partir de um modelo dinâmico não-linear de acumulação de capital e endividamento Externo
}

\author{
Foreign savings and macroeconomic performance: \\ an analysis from a dynamic nonlinear model of capital \\ accumulation and external indebtedness
}

JOSÉ LUÍS OREIRO*****

\begin{abstract}
RESUMO: O objetivo deste artigo é apresentar um modelo dinâmico não-linear de acumulação de capital e dívida externa para avaliar a recente tese defendida por Bresser e Nakano de que uma dívida externa excessiva em países emergentes - que é resultado de grandes déficits em conta corrente - pode produzir não apenas um aumento da fragilidade externa dessas economias, mas também uma estagnação econômica, isto é, uma redução permanente nas taxas de crescimento do produto potencial. Para isso, desenvolveremos um modelo dinâmico no qual (i) um aumento na relação dívida externa/PIB produzirá um aumento menos que proporcional na taxa de investimento, uma vez que uma fração do financiamento externo será usada para a aquisição de ativos não reprodutíveis, como ações e terrenos; (ii) o prêmio de risco país é endógeno, sendo proporcional à dívida externa como fração do PIB. Nesse arcabouço teórico, poderemos mostrar a existência de dois equilíbrios de longo prazo: um equilíbrio com baixa dívida externa e alto grau de utilização de capacidade, e outro equilíbrio com alta dívida externa e baixo grau de utilização de capacidade. Além disso, mostraremos também que - para um certo conjunto de valores de parâmetros - o equilíbrio com alta dívida externa é estável e na vizinhança dessa posição o grau de utilização da capacidade e a relação da dívida externa em relação ao PIB mostrarão uma trajetória temporal caracterizado por flutuações amortecidas.

PALAVRAS-CHAVE: Crescimento com poupança externa; acumulação de capital; modelos neo-kaleckianos.
\end{abstract}

\footnotetext{
* Doutor em economia (IE/UFRJ), professor adjunto do Departamento de Economia da Universidade Federal do Paraná. E-mail: joreiro@sociais.ufpr.br. Submetido: agosto 2003; aceito: setembro $2003 .$.

* O autor agradece ao mestrando Inácio Guerberoff Lanari Bó a ajuda prestada na elaboração dos gráficos apresentados ao longo do artigo. O autor agradece os comentários de Luiz Carlos Bresser Pereira (EAESP/FGV), Gilberto Tadeu Lima (FEA/USP) e Nelson Barbosa Filho (IE/UFRJ). Eventuais falhas são, no entanto, de minha inteira responsabilidade.
} 
ABSTRACT: The objective of this article is to present a non-linear dynamic model of capital accumulation and external debt in order to evaluate the recent thesis defended by Bresser and Nakano that an excessive external debt in emerging countries - which is the result of large current account deficits - can produce not only an increase in external fragility of these economies, but also an economic stagnation, i.e. a permanent reduction in the growth rates of potential output. For this purpose, we will develop a dynamic model in which (i) an increase in the ratio external debt/GDP will produce a less than proportional increase in the rate of investment, since a fraction of the external finance will be used for the acquisition of non-reproducible assets like stocks and land; (ii) the country risk-premium is endogenous, being proportional to external debt as a fraction of GDP. In this theoretical framework, we will be able to show the existence of two long-run equilibrium: an equilibrium with a low external debt and a high degree of capacity utilization, and another equilibrium with a high external debt and a low degree of capacity utilization. Moreover, we will also show that for a certain set of parameters values - the equilibrium with high external debt is stable and in the neighborhood of this position the degree of capacity utilization and the ratio of external debt to GDP will both show a time path characterized by damped fluctuations. KEYWORDS: Growth with foreign savings; capital accumulation; neo-kaleckian models. JEL Classification: O11; E11; O41.

\section{INTRODUÇÃO}

Os defensores da conversibilidade da conta de capitais argumentam que um dos benefícios que esta traz para os países em desenvolvimento é um maior acesso aos mercados internacionais de capitais e, portanto, um fluxo maior de poupança externa para esses países. Dado que quanto maior for a taxa de poupança (interna + externa) maior será o nível de renda per capita da economia no longo prazo, de acordo com o modelo neoclássico de crescimento Solow-Swan; segue-se que os países em desenvolvimento deveriam liberalizar as suas contas de capitais de forma que se estimulasse o aumento do nível de renda per capita, reduzindo, assim, a sua distância com respeito ao nível de renda per capita dos países desenvolvidos.

Essa visão pró-liberalização da conta de capitais se fundamenta, portanto, na hipótese de que o crescimento econômico pode ser estimulado ou induzido pela poupança externa. Como a poupança externa é a contrapartida contábil dos déficits em transações correntes, segue-se que o crescimento dos países em desenvolvimento estaria associado a grandes desequilíbrios na conta de transações correntes do balanço de pagamentos.

A idéia de que a poupança externa é uma condição necessária para o crescimento dos países em desenvolvimento tem sido bastante criticada por autores ligados à tradição estruturalista em macroeconomia. Autores como Cimolli (1988), McCombie e Twirwall (1994) e Curado e Porcile (2002) têm mostrado que o grande problema dos países em desenvolvimento é precisamente a restrição externa ao crescimento. Com efeito, esses países tendem a apresentar uma taxa de crescimento inferior ao potencial em função da "rigidez da balança comercial". De 
fato, a pauta de exportações desses países é especializada em bens cuja elasticidade-renda da demanda é relativamente baixa. Isso faz com que a taxa de crescimento do produto real compatível com o equilíbrio da balança comercial seja igual ou menor do que a dos países desenvolvidos, cuja pauta de exportações é composta principalmente por bens cuja elasticidade-renda da demanda é alta.

Uma segunda linha de argumentação contra a tese de que a poupança externa é necessária para o crescimento dos países em desenvolvimento foi elaborada recentemente por Bresser e Nakano (2003). Para esses autores, o financiamento do crescimento via "poupança externa" tende a gerar uma redução da taxa de crescimento de longo prazo das economias dos países em desenvolvimento devido ao aumento explosivo do endividamento externo que é gerado por essa estratégia de crescimento. Com efeito, esse aumento do grau de endividamento externo torna as economias desses países suscetíveis a crises do balanço de pagamentos, cuja solução exige grandes desvalorizações da taxa nominal e real de câmbio, as quais geram um aumento das taxas de inflação e induzem a adoção de políticas monetária e fiscal restritivas com o intuito de se obterem o controle dos índices inflacionários e a geração de grandes superávits comerciais por intermédio da redução da absorção doméstica. Essas políticas de contenção de demanda têm como efeito a elevação da taxa real de juros e a redução do nível de atividade econômica e do investimento em ampliação da capacidade produtiva. Nas palavras de Bresser e Nakano:

"Depois de alguns anos de enorme acumulação de dívidas externa e interna, a situação financeira se deteriora. Tal deterioração cria expectativas de negativas sobre parte das empresas locais e internacionais [...] e a taxa de investimento diminui, levando a recessão. A conseqüente redução das receitas governamentais aumenta perversamente o déficit orçamentário. Por outro lado, os credores ficam cada vez mais inquietos. O risco-país aumenta, à medida que a relação dívida externa/exportações cresce muito acima do limite de endividamento. Há tentativas de ataques especulativos. A reversão dos fluxos de capital pode começar por contágio, comportamento de manada e profecia que se cumpre por si mesma. O país está então sujeito ao default internacional e a crise interna" (2003, p. 21).

Dado isso, o presente artigo tem por objetivo fazer uma avaliação da hipótese levantada por Bresser e Nakano de que o endividamento externo excessivo pode ter um impacto negativo sobre a performance macroeconômica dos países em desenvolvimento. Mais especificamente, o artigo tem por objetivo isolar os mecanismos econômicos pelos quais o endividamento externo pode gerar uma performance macroeconômica caracterizada por uma baixa utilização da capacidade produtiva e ciclos de expansão e contração do nível de atividade econômica.

A hipótese levantada por Bresser e Nakano, ainda que corroborada pela experiência histórica dos países em desenvolvimento, é incompatível com os modelos tradicionais de macroeconomia aberta — notadamente o modelo padrão MundellFleming. De fato, os modelos convencionais não estabelecem nenhuma relação 
entre o nível de endividamento externo e o grau de utilização da capacidade produtiva. Por outro lado, os modelos tradicionais de ciclo econômico também não estabelecem nenhuma conexão entre as flutuações do nível de endividamento externo e as flutuações do produto real.

Para tanto, o presente artigo desenvolve um modelo pós-keynesiano de crescimento para uma economia aberta, no qual (i) o investimento em capital fixo é uma função não-linear do endividamento externo como proporção do produto e (ii) a taxa de juros doméstica é uma função crescente do endividamento externo devido ao efeito que um maior endividamento (como proporção do PIB) têm sobre o prêmio de risco-país. Essas hipóteses são suficientes para produzir dois valores de equilíbrio de longo prazo para o grau de utilização da capacidade produtiva e para o endividamento externo como proporção do PIB.

Nesse contexto, demonstra-se a existência de uma posição de equilíbrio caracterizada por um baixo nível de endividamento externo e um elevado grau de utilização da capacidade produtiva, bem como de uma posição de equilíbrio caracterizada por um elevado nível de endividamento externo e um baixo grau de utilização da capacidade. Como corolário dessa argumentação segue-se que o endividamento externo, além de certo limite, tem um impacto negativo sobre o nível de atividade econômica.

Um outro resultado interessante do modelo está relacionado com a dinâmica da economia fora do equilíbrio. Com efeito, vamos mostrar que o equilíbrio com baixo endividamento é instável (do tipo trajetória de sela), ao passo que o equilíbrio com alto endividamento - para uma certa constelação de parâmetros do modelo - é estável, sendo que a economia apresentará um movimento oscilatório amortecido em torno dessa posição. Em outras palavras, o grau de utilização da capacidade produtiva e o endividamento externo como proporção do PIB vão apresentar flutuações amortecidas em torno de seus valores de steady-state na proximidade do equilíbrio com alto endividamento. Daqui se segue que o "endividamento externo excessivo" pode gerar os ciclos (amortecidos) de expansão e contração do nível de atividade econômica que caracterizam o típico comportamento stop-andgo das economias em desenvolvimento (cf. Oreiro et alli, 2003).

O comportamento dinâmico da economia em torno da posição de equilíbrio com alto endividamento externo se assemelha muito à visão de Keynes a respeito das propriedades dinâmicas das economias de mercado. De fato, Keynes afirmava que:

"An outstanding characteristic of the economic system in which we live that, whilst it is subject to severe fluctuations [...] it is not violently unstable. Indeed it seems capable of remaining in a chronic condition of subnormal activity for a considerable period" (CWJMK, vol. VII, p. 249).

Dado isso, o presente artigo está estruturado em quatro seções incluindo a presente introdução. Na seção 2 vamos apresentar a estrutura básica do modelo de crescimento. A análise da estabilidade das posições de equilíbrio é feita na seção 3. Por fim, as conclusões são sumarizadas na seção 4 . 


\section{ACUMULAÇÃO DE CAPITAL E ENDIVIDAMENTO EXTERNO: OS BLOCOS FUNDAMENTAIS DO MODELO}

Consideremos uma economia na qual as empresas produzem um bem homogêneo utilizando força de trabalho e matérias-primas importadas. A tecnologia de produção dessa economia é do tipo Leontieff, de tal forma que os coeficientes técnicos de trabalho e de matérias-primas - ou seja, as quantidades de trabalho e de matérias-primas necessárias para a produção de uma unidade de produto — são independentes do nível de produção das firmas. Por simplicidade, vamos considerar uma economia desprovida de progresso tecnológico de forma que a produtividade do trabalho - definida como a recíproca do requisito unitário de mãode-obra - é constante ao longo do tempo.

Tal como é suposto na maior parte dos modelos de crescimento de inspiração pós-keynesiana, vamos supor que as empresas dessa economia possuem poder de mercado e fixam os preços de seus produtos com base num mark-up constante sobre os custos variáveis de produção. Sendo assim, a equação de preço dessa economia é dada por (cf. Taylor, 1989, p. 21):

$$
p=(1+\tau)\left[w b+e p^{*} a_{0}\right]
$$

Onde $p$ é o nível de preços doméstico, $w$ é a taxa de salário nominal, $p$ " é o nível de preços internacional, $e$ é a taxa nominal de câmbio, $b$ é o requisito unitário de mão-de-obra, $a_{0}$ é o requisito unitário de matérias-primas importadas e $\tau$ é a taxa de mark-up.

Seja $r$ a taxa de lucro e $u$ o grau de utilização da capacidade produtiva. Podese demonstrar que a taxa de lucro é dada por:

$$
r=\frac{\tau}{1+\tau} u
$$

De (2) podemos observar que a taxa de lucro é uma função crescente da taxa de mark-up e do grau de utilização da capacidade produtiva. Como a taxa de mark-up é determinada por variáveis de natureza estrutural ${ }^{1}$, pode ser tomada como constante. Dessa forma, as variações da taxa de lucro vão refletir fundamentalmente as variações observadas no nível de utilização da capacidade instalada.

O mercado de bens estará em equilíbrio quando a demanda agregada por bens domésticos for igual ao nível de produção das firmas. Isso exige que:

$$
p C+p I+p E=p X
$$

Onde $p C$ é o valor nominal dos gastos de consumo, $p I$ é o valor nominal dos gastos de investimento, $p E$ é o valor nominal das exportações líquidas e $p X$ é o valor nominal do nível de produção.

\footnotetext{
${ }^{1}$ Mais especificamente, a taxa de mark-up reflete o "grau de monopólio" das empresas, o qual depende (i) do grau de concentração na indústria, (ii) do nível das barreiras à entrada de novos competidores e (iii) do grau de substitubilidade entre os produtos.
} 
Vamos supor a existência de duas classes sociais - capitalistas e trabalhadores - as quais se diferenciam entre si com base na origem dos seus rendimentos — lucros e salários - e com base na propensão a consumir a renda disponível. Nesse contexto, vamos supor que os trabalhadores "consomem tudo o que ganham" de forma que a sua propensão a consumir é igual a um. ${ }^{2}$ Por outro lado, os capitalistas consomem uma fração $c p$ dos seus rendimentos (os quais são constituídos unicamente de lucros), poupando uma fração $s p=(1-c p)$ da sua renda. Sendo assim, o valor nominal dos gastos de consumo é dado por:

$$
p C=w b X+\left(1-s_{p}\right) r p K
$$

Substituindo (4) em (3) temos após os algebrismos necessários que (cf. Taylor, 1989, p. 23):

$$
p I+\left(p E-e p^{*} a_{0} X\right)-s_{p} r p K=0
$$

Dividindo (5) por $X$, obtemos a seguinte expressão:

$$
\frac{I}{X}+\frac{E}{X}-\frac{e p^{*} a_{0}}{p}-s_{p} \tau(1+\tau)^{-1}=0
$$

Onde I/X é a taxa de investimento (investimento como proporção do produto real) e E/X representa o superávit comercial como proporção do produto real.

Para analisarmos o equilíbrio no mercado de bens temos que especificar as funções comportamentais que determinam a taxa de investimento e o superávit comercial como proporção do produto real.

Para tanto, vamos supor que a função investimento dessa economia é dada pela seguinte equação:

$$
\begin{aligned}
& \frac{I}{X}=\alpha_{0}+\alpha_{1}(r-i)+\alpha_{2} z^{\psi} ; 0<\psi<1 \\
& \alpha_{0}>0 ; \alpha_{1}>0 ; \alpha_{2}>0
\end{aligned}
$$

Onde $Z$ é a dívida externa como proporção do produto real.

$\mathrm{Na}$ equação (7) estamos fazendo a hipótese keynesiana convencional de que o investimento é positivamente influenciado pela diferença entre a taxa corrente de lucro - a qual é uma próxi da taxa esperada de retorno dos novos projetos de investimento (cf. Possas, 1987) - e a taxa nominal de juros. ${ }^{3}$ Deve-se ressaltar, contudo, que os modelos pós-keynesianos convencionais de crescimento e distribuição de renda especificam a função investimento em termos da taxa de crescimento do estoque de capital $(I / K)$, em vez de fazê-lo em termos da taxa de investi-

\footnotetext{
${ }^{2}$ Ou seja, a sua propensão a poupar é igual a zero.

3 Por simplicidade, estamos supondo que a taxa esperada de inflação seja igual a zero.
} 
mento (I/X) (cf. Marglin, 1984; Lima, 1999). A escolha de uma ou outra especificação é, no entanto, uma simples questão de conveniência analítica; não havendo nenhuma razão a priori para se optar por uma das referidas especificações.

O elemento novo na função investimento é a dívida externa como proporção do produto real. A sua incorporação na função investimento tem por objetivo apresentar as restrições de financiamento externo à decisão de investimento em capital fixo. Com efeito, tal como salientado por Bresser e Nakano (2003, p.14), o investimento é limitado, numa economia aberta, pela capacidade de importar bens de capital. Nesse contexto, o endividamento externo pode atuar para relaxar a restrição de divisas à compra de bens de capital no exterior, contribuindo, dessa forma, para aumentar o investimento realizado pelos empresários. ${ }^{4}$ Pode-se observar na equação (7) que o efeito do endividamento externo sobre a taxa de investimento é não-linear. Mais especificamente, supõe-se que um aumento do endividamento externo como proporção do produto real vai gerar um acréscimo menos do que proporcional na taxa de investimento. Essa hipótese pode ser justificada com base na idéia de que o endividamento externo não é plenamente destinado ao financiamento do investimento em capital fixo, mas destina-se, em parte, ao financiamento da aquisição de ativos financeiros como, por exemplo, ações e títulos do governo. Sendo assim, o aumento do endividamento externo não vai resultar num acréscimo proporcional da taxa de investimento.

A função de exportações líquidas é dada pela seguinte equação:

$$
\begin{aligned}
& \frac{E}{X}=\varepsilon_{0}-\varepsilon_{1}\left[(1+\tau) \tau^{-1}\right] r \\
& \varepsilon_{0}>0, \varepsilon_{1}>0
\end{aligned}
$$

$\mathrm{Na}$ equação (8) se supõe que as exportações líquidas como proporção do PIB sejam uma função inversa do grau de utilização da capacidade produtiva. Tratase da hipótese convencional de que um aumento do produto interno gere um aumento das importações e, dado o valor das exportações, produza uma redução do saldo da balança comercial. Os efeitos da variação da taxa real de câmbio sobre as exportações líquidas como proporção do PIB são captados pelo termo constante $\varepsilon_{0}$. Com efeito, vamos supor que a taxa real de câmbio seja uma variável exógena no modelo, sendo que variações (exógenas) do câmbio real vão se expressar por meio de um aumento da constante $\varepsilon_{0}$.

Para fecharmos o modelo temos ainda que especificar os determinantes da taxa nominal de juros. Com esse objetivo em mente, vamos supor que a economia

\footnotetext{
${ }^{4} \mathrm{~A}$ inclusão de $\mathrm{Z}$ na função investimento não precisa ser justificada apenas com base na idéia de restrição de divisas. Com efeito, com base na teoria do investimento de Hyman Minsky, o investimento desejado pelas firmas vai aumentar em função de uma redução do risco do tomador e/ou do emprestador. Nesse contexto, o acesso ao mercado internacional de capitais poderia atuar para aumentar o investimento desejado pelas firmas à medida que a diversificação das fontes de financiamento contribuiria tanto para a queda do risco do tomador como para a redução do risco do emprestador. Sobre a teoria Minskiana do investimento, ver Minsky (1975).
} 
em consideração exiba conversibilidade plena da sua conta de capitais — ou seja, existe mobilidade perfeita de capitais no sentido usado no modelo MundellFleming - e que prevaleça o regime de câmbio fixo. Nesse contexto, a taxa nominal de juros é determinada com base na paridade descoberta da taxa de juros, sendo dada pela seguinte equação:

$$
i=i^{*}+\rho(9)
$$

Onde $i^{*}$ é a taxa de juros internacional e $\rho$ o prêmio de risco país.

Tal como Bresser e Nakano (2002) e Oreiro (2002), vamos supor que o prêmio de risco seja endógeno, sendo dado pela seguinte equação:

$$
\begin{aligned}
& \rho=\rho_{0}+\rho_{1} z \\
& \rho_{0}>0, \rho_{1}>0
\end{aligned}
$$

$\mathrm{Na}$ equação (10) estamos supondo que o prêmio de risco é uma função crescente da dívida externa como proporção do produto real. A idéia é que quanto maior for o endividamento externo maior será o volume de compromissos externos do país na forma de juros e amortizações sobre o principal, aumentando, assim, o risco de default.

Substituindo (10) em (9) e a resultante em (7), obtemos a seguinte expressão:

$$
\begin{aligned}
& \frac{I}{X}=B_{0}+\alpha_{1} r+\left[\alpha_{2} z^{\psi}-\alpha_{1} \rho_{1} z\right] \\
& \mathrm{B}_{0}=\alpha_{0}-\alpha_{1}{ }^{{ }^{*}}-\alpha_{1} \rho_{0}
\end{aligned}
$$

Podemos observar na equação (11) que a taxa de investimento depende apenas da taxa corrente de lucro e do endividamento externo como proporção do produto real. Diferenciando (11) com respeito a $z$, obtemos a seguinte expressão:

$$
\frac{\partial(I / X)}{\partial z}=\psi \alpha_{2} z^{\psi-1}-\alpha_{1} \rho_{1}
$$

A equação (12) mostra que o efeito de um aumento do endividamento externo sobre a taxa de investimento depende do nível desse endividamento. De fato, para valores baixos de $z$ o sinal da derivada parcial apresentada na equação (12) será positivo, ou seja, um aumento do endividamento externo vai produzir um aumento da taxa de investimento. Para valores altos de $z$, contudo, o sinal dessa derivada parcial será negativo, de forma que um aumento do endividamento externo estará associado a uma redução da taxa de investimento. Pode-se mostrar que o valor crítico de $z$ acima do qual a taxa de investimento torna-se uma função inversa do endividamento externo é dado por

$$
z^{*}=\left(\frac{\psi \alpha_{2}}{\alpha_{1} \rho_{1}}\right)^{\left(\frac{1}{1-\psi}\right)}
$$


A relação entre a taxa de investimento e o endividamento externo como proporção do produto real pode ser visualizada por meio da figura 1 , abaixo: ${ }^{5}$

Figura 1

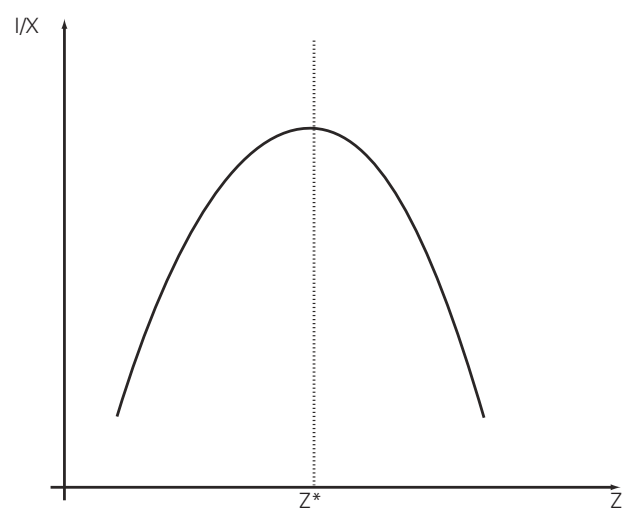

Substituindo (8) e (11) em (6), obtemos a seguinte expressão: ${ }^{6}$

$$
r=\left(\frac{B_{0}+\varepsilon_{0}}{\varepsilon_{1}(1+\tau) \tau^{-1}-\alpha_{1}}\right)+\left(\frac{\alpha_{2} z^{\psi}-\alpha_{1} \rho_{1} z}{\varepsilon_{1}(1+\tau) \tau^{-1}-\alpha_{1}}\right)-\left(\frac{(1+\tau)^{-1}\left(s_{p} \tau+\phi\right)}{\varepsilon_{1}(1+\tau) \tau^{-1}-\alpha_{1}}\right)
$$

Onde $\phi=\frac{e p^{\prime} a_{0}}{w b+e p^{2} a_{0}}$ é a participação dos insumos importados no custo variável. Diferenciando (12) com respeito a $r$ e $z$, obtemos a seguinte expressão:

$$
\frac{\partial r}{\partial z}=\frac{\psi \alpha_{2} z^{\psi-1}-\alpha_{1} \rho_{1}}{\varepsilon_{1}(1+\tau) \tau^{-1}-\alpha_{1}}
$$

$\mathrm{Na}$ equação (13) podemos constatar que o sinal de $\partial r \partial z$ será positivo quando $\mathrm{z}<\mathrm{z}^{*}$ e será negativo quando $\mathrm{z}>\mathrm{z}^{*}$. Sendo assim, a relação entre a taxa de lucro (ou o grau de utilização da capacidade produtiva) e o endividamento externo como proporção do produto real é não-linear, podendo ser visualizada por meio da figura 2, a seguir: ${ }^{7}$

\footnotetext{
${ }^{5}$ Deve-se fazer uma ressalva importante. Com base na equação (11), a figura 1 não será exatamente uma parábola. De fato, o desenho geométrico de uma parábola só seria possível se a equação (11) fosse quadrática em Z. Contudo, admitindo-se a hipótese de que $Z$ não pode ser negativo (ou seja, a idéia de que países emergentes são necessariamente devedores líquidos) segue-se que a curva descrita na figura 1 terá um ramo ascendente na região em que $\mathrm{z}<\mathrm{z}^{*}$, e um ramo ascendente na região em que $\mathrm{z}>\mathrm{z}^{*}$. Daqui se segue que do ponto de vista puramente qualitativo a curva apresentada na figura 1 pode ser aproximada por uma parábola.

${ }^{6} \mathrm{Na}$ equação (12) estamos supondo que a sensibilidade das exportações líquidas às variações da taxade lucro é maior do que a sensibilidade do investimento às variações dessa taxa. Essa hipótese é necessária para garantir que o valor de equilíbrio da taxa de lucro seja positivo.
}

${ }^{7}$ Vide comentários apresentados na nota 5 


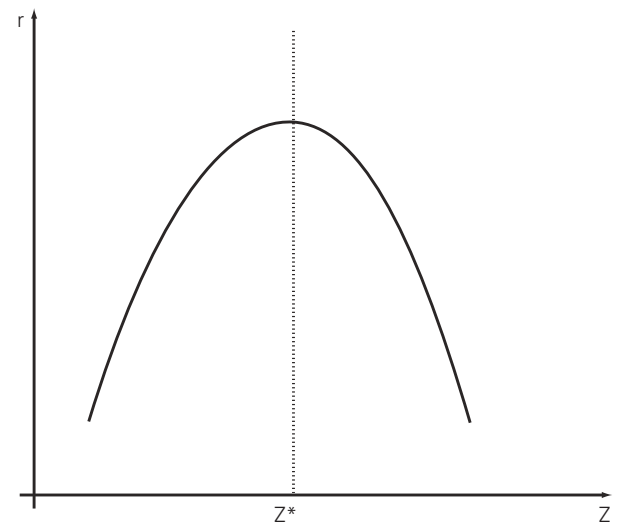

\section{DINÂMICA DA DÍVIDA EXTERNA E EQUILÍBRIOS MÚLTIPLOS.}

Seguindo Simonsen e Cysne (1995), a equação diferencial que descreve a dinâmica temporal da dívida externa é dada por:

$$
\dot{D}=i D-H
$$

Onde $D$ é o estoque total de endividamento externo e $H$ é a transferência líquida de recursos para o exterior.

Diferenciando $z$ com respeito ao tempo, obtemos a seguinte expressão:

$$
\dot{z}=\frac{\dot{D}}{X}-\frac{\dot{X}}{X} \frac{D}{X}
$$

Substituindo (14) em (15) e supondo que a taxa de crescimento do produto real seja exógena e igual a $g,{ }^{8,9}$ obtemos a seguinte expressão:

\footnotetext{
${ }^{8}$ Essa suposição é necessária uma vez que o modelo aqui apresentado não possui nenhuma equação capaz de determinar a taxa de crescimento do produto. A suposição usual dos modelos pós-keynesianos de crescimento e distribuição de renda é que, em função da hipótese de coeficientes fixos, a taxa de crescimento do estoque de capital é igual à taxa de crescimento do produto. Contudo, como a utilização da capacidade produtiva é uma variável endógena neste modelo - e em outros modelos pós-keynesianos - segue-se que essa igualdade só é válida em steady-state, uma vez que nessa posição de repouso o grau de utilização da capacidade produtiva é constante. Fora do steady-state, o grau de utilização da capacidade produtiva pode variar ao longo do tempo de forma que a taxa de crescimento do produto poderá ser maior ou menor do que a taxa de crescimento do estoque de capital.

${ }^{9}$ A exogeneidade da taxa de crescimento do produto real pode ser observada também no modelo de crescimento de Kaldor (1957). Nesse modelo, a taxa de crescimento do produto real é igual à taxa de crescimento da força de trabalho mais a taxa de crescimento da produtividade. Esta última é determinada pelos parâmetros da assim chamada função de progresso técnico, que relaciona o crescimento do produto por trabalhador com o crescimento do capital por trabalhador. O ponto a ser destacado é que no modelo de Kaldor a taxa de crescimento da produtividade é determinada de forma independente do resto do modelo, podendo, assim, ser caracterizada como "exógena" do ponto de vista das demais
} 


$$
\dot{z}=(i-g) z-\frac{H}{X}
$$

A transferência líquida de recursos para o exterior nada mais é, na economia em consideração, do que o valor das exportações líquidas. ${ }^{10}$ Sendo assim, a expressão final para a dinâmica da dívida externa como proporção do PIB é dada por:

$$
\dot{z}=\rho_{1} z^{2}+\left(\rho_{0}-g\right) z-\varepsilon_{0}+\varepsilon_{1}(1+\tau) \tau^{-1} r
$$

A equação (17) é uma equação diferencial não-linear em $z$ e $r$. Para analisarmos a dinâmica dessas variáveis precisamos especificar uma outra equação diferencial.

Para tanto, vamos supor que o ajuste no mercado de bens é lento, ou seja, que o grau de utilização da capacidade produtiva se ajusta de forma contínua à situações de excesso de oferta ou de demanda agregada. Como as variações do grau de utilização da capacidade se refletem em variações da taxa de lucro, podemos escrever a seguinte equação diferencial:

$$
\dot{r}=\Phi\left(B_{0}+\alpha_{1} r+\left(\alpha_{2} z^{\psi-1}-\alpha_{1} \rho_{1}\right) z+\varepsilon_{0}-\varepsilon_{1}(1+\tau) \tau^{-1} r-(1+\tau)^{-1}\left(s_{p} \tau+\phi\right)\right)
$$

As expressões (17) e (18) formam um sistema de equações diferenciais nãolineares que determinam a dinâmica da taxa de lucro e da dívida externa como proporção do produto real.

Em steady-state temos que a taxa de lucro e o endividamento externo são constantes ao longo do tempo. Isso nos permite definir o lócus $r=0$ e o lócus $z=0$, cujas inclinações são dadas respectivamente pelas seguintes equações:

$$
\begin{aligned}
& \left(\frac{\partial r}{\partial z}\right)_{\mid \dot{ }=0}=\frac{\psi \alpha_{2} z^{\psi-1}-\alpha_{1} \rho_{1}}{\varepsilon_{2}(1+\tau) \tau^{-1}-\alpha_{1}} \\
& \left(\frac{\partial r}{\partial z}\right)_{\mid i=0}=-\frac{\left(2 \rho_{1} z+\left(\rho_{0}-g\right)\right)}{\varepsilon_{1}(1+\tau) \tau^{-1}}(20)
\end{aligned}
$$

$\mathrm{Na}$ seção anterior foi demonstrado que o lócus que descreve as combinações de $r$ e $z$ para as quais o mercado de bens se encontra em equilíbrio tem o formato de uma parábola com concavidade voltada para baixo (figura 2 ). ${ }^{11} \mathrm{Na}$ equação (20) podemos constatar que - supondo $\rho_{0}>g$ e que $z$ não pode ser negativo - o lócus que descreve as combinações de $r$ e $z$ para as quais a dívida externa é constante ao longo do tempo tem inclinação negativa para todos os valores de $z .^{12}$

equações. Daqui se segue que a exogeneidade da taxa de crescimento do produto real não implica a inexistência de uma teoria a respeito dos determinantes dela, mas apenas que essa taxa é determinada "fora" do modelo que está sendo apresentado.

\footnotetext{
${ }^{10}$ Estamos supondo que o saldo da balança de serviços não-fatores seja igual a zero.

${ }^{11}$ Vide comentários apresentados na nota 5, páginas 192-193.

${ }^{12}$ Deve-se ressaltar, contudo, que lócus z=0 não é uma linha reta. Contudo, dado que $Z$, nas condições aqui supostas, não pode ser negativo e que $\rho 0>$ g, segue-se que o referido locus terá necessariamente
} 
Sendo assim, a configuração de equilíbrio de longo prazo da economia em consideração pode ser visualizada por meio da Figura 3.

Figura 3

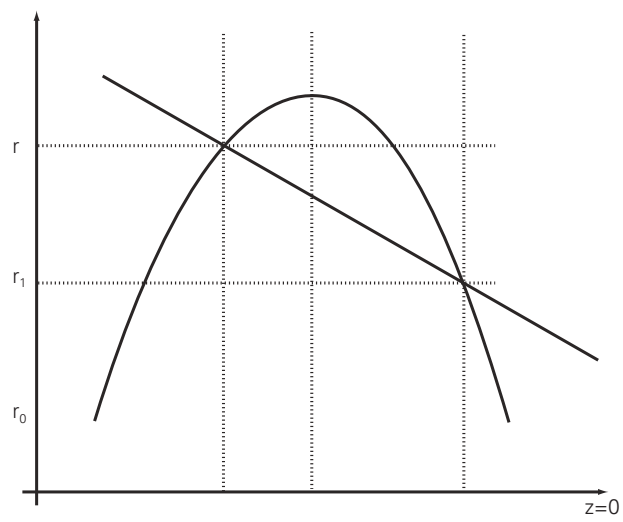

$\mathrm{Na}$ figura 3 observamos a existência de duas posições de equilíbrio de longo prazo para a economia em consideraçã $\mathrm{O}_{z^{*}}{ }^{13} \mathrm{~A}$ primeira - situada à esquerda de $z^{*}$ - é caracterizada pela existência de um baixo nivel de endividamento externo como proporção do produto e uma elevada taxa de lucro (e, portanto, um elevado grau de utilização da capacidade produtiva). Vamos denominar essa posição de equilíbrio com baixo endividamento. A segunda — situada à direita de $z^{*}$ —é caracterizada pela existência de um elevado endividamento externo como proporção do produto real e uma baixa taxa de lucro (e, portanto, um baixo grau de utilização da capacidade produtiva). Vamos denominar essa posição de equilíbrio com alto endividamento.

Como corolário dessa conclusão segue-se que, se a economia apresentar um nível de endividamento externo maior que $z^{\prime \prime}$, então o nível de equilíbrio da utilização da capacidade produtiva será menor do que o prevalecente numa situação em que o endividamento externo fosse inferior a $z$ ". Daqui se segue que o "endividamento externo excessivo" resulta num elevado nível de ociosidade da capacidade produtiva existente e numa baixa taxa de retorno sobre o capital, configurando, assim, uma situação de estagnação econômica.

Para analisarmos a estabilidade das posições de equilíbrio de longo prazo da economia em consideração, temos inicialmente que linearizar o sistema em torno

inclinação negativa. Sendo assim, do ponto de vista puramente qualitativo, poderemos aproximar esse lócus através de uma linha reta.

${ }^{13}$ Está claro que o caso representado na figura 3 não é o único possível. Com efeito, existem ainda outros dois casos possíveis. Um em que as curvas não se interceptam em nenhum ponto e um no qual as curvas se tangenciam em um único ponto. Contudo, para os fins do presente artigo o caso de interesse é o representado pela figura 3 . 
de sua posição de equilíbrio. Dessa forma, obtemos o seguinte sistema de equações diferenciais:

$$
\begin{aligned}
& \dot{r}=\left[\alpha_{1}-\varepsilon_{1}(1+\tau) \tau^{-1}\right]\left(r-r^{*}\right)+\left[\psi z^{\psi-1} \alpha_{2}-\alpha_{1} \rho_{1}\right]\left(z-z^{*}\right) \\
& \dot{z}=\left[\varepsilon_{1}(1+\tau) \tau^{-1}\right]\left(r-r^{*}\right)+\left[2 \rho_{1} z+\left(\rho_{0}-g\right)\right]\left(z-z^{*}\right)
\end{aligned}
$$

Calculando o determinante e o traço da matriz jacobiana associada ao sistema formado pelas equações (21) e (22), obtemos as seguintes expressões:

$$
\begin{aligned}
& D E T=\frac{\partial F_{1}}{\partial r} \frac{\partial F_{2}}{\partial z}-\frac{\partial F_{2}}{\partial r} \frac{\partial F_{1}}{\partial z} \\
& D E T=\frac{\partial F_{1}}{\partial r} \frac{\partial F_{2}}{\partial z}-\frac{\partial F_{2}}{\partial r} \frac{\partial F_{1}}{\partial z}
\end{aligned}
$$

onde:

$$
\begin{array}{lll}
\frac{\partial F_{1}}{\partial r}=\alpha_{1}-\varepsilon_{1}(1+\tau) \tau^{-1}<0 & \frac{\partial F_{1}}{\partial z}=\psi z^{\psi-1} \alpha_{2}-\alpha_{1} \rho_{1} & (25 \mathrm{a})(25 \mathrm{~b}) \\
\frac{\partial F_{2}}{\partial r}=\varepsilon_{1}(1+\tau) \tau^{-1}>0 & \frac{\partial F_{2}}{\partial z}=2 \rho_{1} z+\left(\rho_{0}-g\right)>0 & (25 \mathrm{c})(25 \mathrm{~d})
\end{array}
$$

O sinal do determinante da matriz jacobiana vai depender do sinal de (25b), que, por sua vez, depende de o endividamento externo como proporção do produto real ser maior ou menor do que $z^{*}$. Se $z<z^{*}$, então (25b) será positivo de forma que o determinante da matriz jacobiana será negativo. Sendo assim, o equilíbrio com baixo endividamento será instável do tipo trajetória de sela (cf. Takayama, 1993, pp. 407-408). Por outro lado, se $z>z^{*}$ então o sinal de (25b) será negativo. Neste caso, o determinante pode ser positivo ou negativo.

Supondo que o determinante seja positivo - o que eliminaria uma trajetória de sela para o caso do equilíbrio com alto endividamento - teríamos ainda que analisar o sinal do traço da matriz jacobiana. Para que o equilíbrio com alto endividamento seja estável é necessário que o traço da referida matriz seja negativo (Ibid, pp. 407-408). Isso vai acontecer se a seguinte condição for atendida:

$$
z<\frac{\varepsilon_{1}(1+\tau) \tau^{-1}-\alpha_{1}-\left(\rho_{0}-g\right)}{2 \rho_{1}}=z^{* *}
$$

Dado que a posição de equilíbrio com alto endividamento exige que $z>z^{\prime \prime}$, segue-se que a estabilidade dessa posição de equilíbrio demanda que $\mathrm{z}^{*}<z^{* \prime *}$; ou seja, é necessário que $z$ esteja situado no seguinte intervalo:

$$
\left(\frac{\psi \alpha_{2}}{\alpha_{1} \rho_{1}}\right)^{\left(\frac{1}{1-\psi}\right)}<z<\frac{\varepsilon_{1}(1+\tau) \tau^{-1}-\alpha_{1}-\left(\rho_{0}-g\right)}{2 \rho_{1}}
$$


Por outro lado, para que $z^{*}<z^{* * *}$, a seguinte condição deve ser atendida:

$$
g>g^{*}=2 \rho_{1}\left(\frac{\psi \alpha_{2}}{\alpha_{1} \rho_{1}}\right)^{\left(\frac{1}{1-\psi}\right)}-\varepsilon_{1}(1+\tau) \tau^{-1}+\alpha_{1}+\rho_{0}
$$

Em palavras: a taxa de crescimento do produto deve ser maior do que um certo valor crítico $g^{*}$ para que o equilíbrio com alto endividamento possa ser estável. Com efeito, se essa condição não for atendida, então $z^{*}>z^{* * *}$, de forma que o equilíbrio com alto endividamento será necessariamente instável. Contudo, o atendimento de (28) não é suficiente para garantir a estabilidade dessa posição de equilíbrio. Além dessa condição é necessário que $z$ esteja situado no intervalo definido pela expressão (27) - o que mostra que existe um limite superior ao endividamento externo como proporção do produto real, acima do qual o equilíbrio com alto endividamento torna-se instável - e que o determinante da matriz jacobiana seja estável.

As condições de estabilidade das posições de equilíbrio dessa economia são resumidas na tabela 1 , apresentada a seguir.

Tabela 1

\begin{tabular}{ccc}
\hline & Estabilidade & Instabilidade \\
\hline Equilíbrio com baixo endividamento & Não definido & $\mathrm{z}<\mathrm{z}^{*}$ \\
\hline Equilíbrio com alto endividamento & $\mathrm{g}>\mathrm{g}^{*}$ & $\mathrm{~g}<\mathrm{g}^{*}$ \\
& $\mathrm{z}^{*}<\mathrm{z}<\mathrm{z}^{* *}$ & ou $\mathrm{z}>\mathrm{z}^{* *}$ \\
\hline
\end{tabular}

Supondo que as condições de estabilidade do equilíbrio com alto endividamento sejam atendidas, a dinâmica de $r$ e $z$ em torno dessa posição pode ser de dois tipos, a saber: um nódulo estável ou uma espiral convergente. A dinâmica será descrita por uma espiral convergente se as raízes da equação característica associada ao sistema formado por (21) e (22) forem negativas.

A equação característica do sistema é dada por:

$$
\lambda^{2}-\lambda\left(\frac{\partial F_{2}}{\partial z}+\frac{\partial F_{1}}{\partial r}\right)-\left(\frac{\partial F_{2}}{\partial r} \frac{\partial F_{1}}{\partial} \frac{\partial F_{1}}{\partial r} \frac{\partial F_{2}}{\partial z}\right)=0
$$

Pode-se demonstrarque o discriminantede (29) é dado por:

$$
\Delta=\left(\frac{\partial F_{2}}{\partial z}-\frac{\partial F_{1}}{\partial r}\right)^{2}+4 \frac{\partial F_{2}}{\partial r} \frac{\partial F_{1}}{\partial z}
$$

Sabemos que para $z>z^{*}$ temos que, de forma que o sistema pode apresentar uma dinâmica do tipo espiral convergente. Essa ambigüidade, contudo, pode ser resolvida ao se construir o digrama de fases referente à economia em consi- 
deração. Tendo como base esse diagrama - apresentado na figura 4, abaixo - , podemos afirmar que na região em que $z>z^{\prime \prime}$, haverá uma dinâmica do tipo espiral convergente.

Figura 4

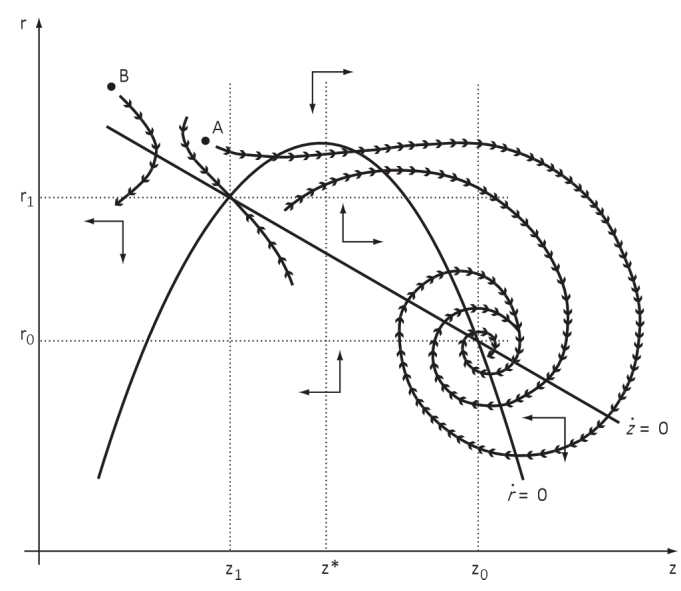

$\mathrm{Na}$ figura 4 podemos observar que a trajetória no tempo do grau de utilização da taxa de lucro e da dívida externa como proporção do PIB depende dos valores iniciais de $r$ e $z$. Com efeito, se $z>z^{\prime \prime}$ então a economia vai apresentar flutuações amortecidas em torno da posição de equilíbrio com alto endividamento. Mais especificamente, o grau de utilização da capacidade produtiva e o endividamento externo como proporção do produto real vão flutuar em torno de seus valores de equilíbrio de longo prazo.

Uma análise qualitativa da dinâmica da economia em torno da posição de equilíbrio com alto endividamento mostra que a fase de expansão da produção real ao longo do ciclo econômico é caracterizada por um aumento inicial do endividamento externo como proporção do PIB, movimento esse que é revertido antes de a produção real entrar numa trajetória descendente. Ou seja, a queda do endividamento externo antecede a queda do grau de ocupação da capacidade produtiva. A redução do endividamento externo continua mesmo após o início da trajetória de queda do grau de utilização da capacidade produtiva. Contudo, em algum ponto ao longo dessa trajetória, o movimento de redução do endividamento externo é revertido e a economia passa a apresentar uma trajetória caracterizada pela redução do nível de utilização da capacidade produtiva e aumento do endividamento externo. $\mathrm{O}$ aumento da dívida externa como proporção do produto real acaba por interromper a trajetória de queda do nível de atividade econômica, fazendo com que a economia entre novamente numa trajetória de expansão da capacidade produtiva. Essa dinâmica se assemelha ao movimento de stop-and-go que caracteriza os países em desenvolvimento com alto nível de endividamento externo.

Se as condições iniciais da economia forem tais que $z<z^{*}$, então poderemos observar dois tipos diferentes de trajetórias para $r$ e $z$. Se a economia estiver inicial- 
mente situada num ponto como o ponto A da figura 4, então acabará convergindo para o equilíbrio com alto endividamento. Contudo, se a economia estiver inicialmente situada num ponto como o ponto B, então vai descrever uma trajetória caracterizada por uma redução cumulativa do grau de utilização da capacidade produtiva e do endividamento externo como proporção do PIB real.

\section{CONCLUSÃO}

Ao longo do presente artigo foi desenvolvido um modelo dinâmico não-linear de inspiração pós-keynesiana para avaliar a tese defendida recentemente por Bresser e Nakano de que um "endividamento externo excessivo" pode ter um impacto negativo sobre a performance macroeconômica dos países em desenvolvimento. Os resultados obtidos por esse modelo nos permitem concluir que um alto nível de endividamento externo pode produzir uma posição de equilíbrio de longo prazo caracterizada pela existência de uma grande capacidade ociosa. Para uma certa constelação de valores dos parâmetros do modelo, o equilíbrio com alto endividamento será estável, apresentando uma dinâmica do tipo espiral convergente. Daqui se segue que, na proximidade dessa posição de equilíbrio, a economia vai apresentar flutuações (amortecidas) do grau de utilização da capacidade produtiva e do endividamento externo como proporção do produto real, as quais se assemelham ao comportamento típico de stop-and-go das economias em desenvolvimento com um elevado endividamento externo.

\section{REFERÊNCIAS BIBLIOGRÁFICAS}

Bresser-Pereira, L.C; Nakano, Y. (2002). "Uma estratégia de desenvolvimento com estabilidade”, Revista de Economia Política, vol. 22, $\mathrm{n}^{\circ} 3$.

(2003). Crescimento econômico com poupança externa? Revista de Economia Política, vol. $23, \mathrm{n}^{\circ} 2$.

Cimoli, M. (1988) "Technological gaps and institutional asymmetries in a north-south model with a continuum of goods", Metroeconomica, vol. 39, n 111.

Curado, M; Porcile, G. (2002). "Rigidez na balança comercial e movimentos de capital: uma abordagem estruturalista”, Revista Brasileira de Economia.

Kaldor, N. (1957). “A model of economic growth”. Economic Journal, vol. 67, pp. 591-624.

Keynes, J.M. (1973). The Collected Writings of John Maynard Keynes. Editado por D.E. Moggridge. Macmillan: Londres [no texto é referenciado por CWJMK].

Lima, G. T. (1999). "Progresso tecnológico endógeno, crescimento econômico e distribuição de renda”, in Lima, G.T. et alli. Macroeconomia Moderna: Keynes e a Economia Contemporânea. Campus: Rio de Janeiro.

Marglin, S. (1984a). Growth, Distribution and Prices. Harvard University Press: New York.

McCombie, J.S.L.; Thirlwall, A.P. (1994) Economic Growth and Balance of Payments Constraint. New York: St Martin's Press.

Oreiro, J.L. (2002). "Prêmio de risco endógeno, metas de inflação e câmbio flexível. Revista de Economia Política, vol. 22, $\mathrm{n}^{\circ} 3$.

Oreiro, J.L.; Sicsú, J.S.; De Paula, L.F. (2003). Uma Alternativa Keynesiana para o Crescimento Susten- 
tado da Economia Brasileira. Anais do VIII Encontro Nacional de Economia Política. Florianópolis.

Possas, M.L. (1987). Dinâmica da Economia Capitalista. Brasiliense: São Paulo.

Simonsen, M.H.; Cysne, R.P. (1995). Macroeconomia. Atlas: São Paulo.

Takayama, A. (1993). Analytical Methods in Economics. The University of Michigan Press: Michigan. Taylor, L. (1989). Macroeconomía Estruturalista. Trillas: Cidade do México. 